\title{
Self-assessment in Industrial Engineering. Pilot Test in Graphic Engineering at the Polytechnic University of Catalunya-BarcelonaTech
}

\author{
Anna Pujol-Ferran ${ }^{(\bowtie)}(\mathbb{D})$ and Oscar Farrerons-Vidal (D) \\ Escola d'Enginyeria de Barcelona Est-EEBE, Polythecnic University \\ of Catalunya-Barcelona Tech, C/Eduard Maristany 10-14, 08019 Barcelona, Spain \\ \{anna.pujol.ferran, oscar.farrerons\}@upc.edu
}

\begin{abstract}
We present a study on Self-evaluation in the subject of Graphic Engineering in industrial engineering degrees. It has been implemented at the Polytechnic University of Catalunya in its Terrassa campus (Barcelona). This pilot project started in the 2017-18 academic year and it has continued in 201819 school year. The research begins with a survey completed by the students after they have developed and presented the final project of Graphic Engineering. Students must respond about the contents and competences they acquire throughout the course.

Although the survey also asks for teamwork on the whole subject, we will focus on data corresponding to the project and self-evaluate it to its final result.

Students must assess their learning from different graphic skills such as: pieces representation, dimensioning, sections and the knowledge of 3D geometry.

The self-assessment is not yet a binding evaluation, but it helps to obtain more consensual assessment, taking into account, the teacher evaluation first, without underestimating what the student does.
\end{abstract}

Keywords: Self-evaluation $\cdot$ Graphic engineering $\cdot$ Project $\cdot$ Skills

\section{Introduction. Self-evaluation and Its Context}

This pilot test has been developed at Higher School of Industrial, Aerospace and Audiovisual Engineering of Terrassa (ESEIAAT) belonging to UPC (Polytechnic University of Catalunya). It is an ingrained engineering school with a close regional scope of great industrial importance. Graphic Engineering subject is taught to 260 students by 10 professors.

Like all university education, the field of engineering has also evolved in recent years, with new methodologies to improve in all teaching areas. One of these areas, the evaluation is being experimented new formulas, denying the classical evaluationqualification by the teacher. New forms of evaluation are emerging with all naturalness such as co-evaluation, shared evaluation, democratic evaluation, dialogue qualification and self-evaluation.

Self-evaluation is the assessment that students make about themselves or about a process and/or personal result. The E.C.T.S (European Credit Transfer) system has 
modified the relationship between teacher-student-learning process, with methodological and organizational changes.

The main changes in evaluation are:

- continuous and formative evaluation, more than final and summative

- evaluation of learning process (not only the apparent final grade)

- evaluation of different types of learning and skills

- evaluation to improve, not only as a control [1].

Evaluation has a positive effect on student learning when it relates to authentic tasks, it represents reasonable demands. This encourages students to use knowledge in a realistic context, which motivates the development of a wide variety of skills and is perceived as beneficial to long-term [2].

Specific objectives are set out from the use of new methodologies in teachinglearning and evaluation towards [3]:

- Strengthen the autonomy of students, creative thinking, reflective and critical, and the ability to self and co-evaluation.

- Interact socially and professionally with their environment through the study of cases, proposing solutions to problems and working in a collaborative way.

- Checking if the work that incorporates self-reflection reinforces students' learning.

- Analysing critically and providing proposals for improvement in the development of individual and collaborative work and put them into practice.

Likewise, these valuations become individual correction factors that, applied to the common qualification of the project, allow to obtain specific punctuations for each team's student [4].

\section{Self-assessment in Graphic Engineering}

A popular method for projects evaluation is used by engineering teachers with Evaluation Instruments [5], based on objective criteria, agreed between different parts of the subject. In addition, these criteria are previously communicated, so students know them very well. This practice avoids note claims, because the criteria are well established, although it is common for students to ask for corrections.

Group feedback significantly increases in group projects [6], where the students inform in writing the common errors committed, concepts that have detected when they are not clear, and other doubts.

This study aims to compare the self-assessment survey that began in the course 2017-2018 in which the results in Engineering Graphic of 1st year, 135 self-evaluated students were evaluated [7]. In this 2018-19 academic year, 220 students have been self-evaluated. 
Both in the past and this year in which the self-assessment survey was carried out, results have not been binding in the final grade of the subject.

It should be noted that in the subject of Graphic Engineering taught in the first semester on the first year of undergraduate studies, the students are still adapting to university, its operation, its infrastructures and equipment, the dynamics of the classes and teachers. These students are 18-19 years old on average.

\subsection{Dynamics of the Graphic Engineering Subject}

The general aim of Graphic Engineering in the first year is the apprenticeship about the representation of plans, both individual or pieces as planes of objects together, assemblies, explosions, etc.

The focus of the subject is practical. Students develop a group project of 3 people between 3-6 weeks. During the classes, an exhaustive follow-up is carried out.

The achievement contains the following parts:

- idea-approach

- sketch-measurement

- representation of plans

- memory development

- oral-visual presentation before the class

It should be noted that there is a follow-up of the project and there are tutorials by the teacher, both in person and online, since students can send parts of the project by email and they are reviewed by the teacher.

Consequently, not only is there a resolution of doubts, but in most cases, they already represent a first project correction.

A potential application is found when the project is defended in oral presentations scheduled during last class-session of the subject. In an oral-visual presentation, each group of 3 students has 10-12 min to explain their project: objectives, approach, development and conclusions. After the presentation, the classmates must make contributions and oral evaluations of each project.

Teacher presents an assessment at the end of each presentation where he comments on strengths and achievements of each project but also weak or unpalatable points.

At this moment, each student, individually, can make an assessment of their work, after listening to the contributions of both, peers and teacher, and has more arguments for self-evaluation.

\subsection{Self-assessment Surveys}

Self-evaluation is intended for a person to make an assessment of himself or on a process and/or personal result [8]. 
A fundamental issue about self-assessment survey includes 3 aspects to be assessed: project, group work, and subject.

The project evaluation and subject evaluation are personal valuations, about oneself. On the other hand, assessment of group work is a group co-evaluation, an evaluation among students from the same group, referring to their contribution [9].

Each of the 3 parts include: 8 questions about the project, 5 questions about the group work and 5 about the subject. In total there are 18 questions. Students are assessed with the possibility of 5 ratings notes (from 1 to 5), with 1 being the lowest and 5 being the highest.

The survey asks about some specific aspects of the projects, such as:

- The representation of pieces

- The dimensioning of the views

- The representation of sections

- 3D geometry knowledge

In addition, they are asked in a more general way: the time allocated to the project, the functioning and cohesion of the work team and if the objectives of the subject have been achieved.

\subsection{Survey Processing}

From the self-assessment surveys, a project note has been collected, which is given by the student himself. The numbering of self-evaluation has the following equivalence:

- 5 - Excellent $(9-10)$

- 4 - Notable $(7-8,99)$

- 3 - Approved $(5-6,99)$

- 2 - Suspense $(3-4,99)$

- 1 - Deficient $(0-2,99)$

Ratings notes are ones the student himself puts on, referent to the project he/she has made. Therefore, we present the results of two studies:

- PROJ_EG. The self-assessing notes of Graphic Engineering Project-

- DES_PROJ_EG. The lag of notes comparing self-assessment with the real score corrected by teacher of the Graphic Engineering Project.

For the phase shift tables, the following 5 values will be taken into account:

- Same note: When student self-evaluates with the same grade that teacher has evaluated, the grade coincides.

- Bottom note -1 : When real grade obtained by the student is a lower level than grade which he has self-evaluated. 
- Bottom note -2 : When real grade obtained by the student is 2 levels lower than grade which he has self-evaluated. In this case, student has a very optimistic perception how he is doing, because afterwards he produces very inferior grades.

- Top note +1 : When real grade obtained by the student is a higher level than grade which he has self-evaluated. Therefore, in this case, the student thinks that he is doing more worse, than he really does afterwards.

- Top grade +2: When real grade obtained by the student is 2 levels higher than grade which he has self-evaluated. We confirm we have not found any case.

\section{Self-evaluation Results}

The most outstanding results of the course 17-18 are, taking into account the 135 processed surveys of the participating students:

\subsection{PROJ_EG 17-18. The Notes that Self-evaluate the Project in Course 2017-18}

Some considerable numbers: $92 \%$ of students value their project with a high score, which 54\% do with a note of noteworthy. Only one student among the 135 respondents believes that they have suspended the project (Fig. 1).

\section{PROJECT SELF-EVALUATION- EGE 2017-18}

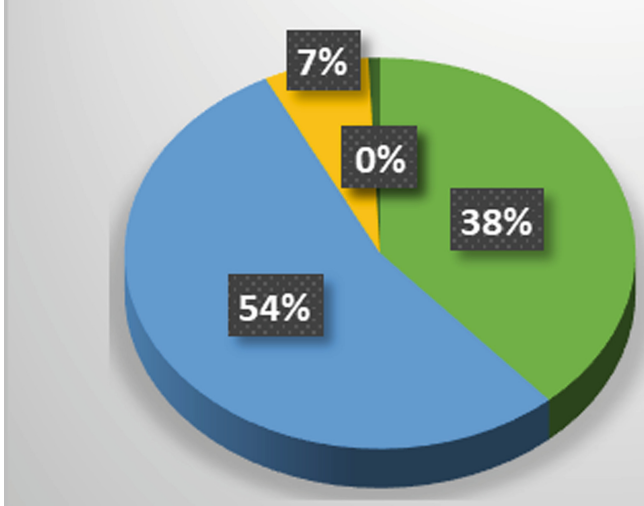

5- Excellent (9-10)

4- Remarkable (7-8,99)

3- Approved $(5-6,99)$

4- Suspense (3-4,99)

घ- Deficient ( 0-2,99)

Fig. 1. PROJ_EG 17-18. Ratings Project notes in the course 2017-18 
3.2 DES_PROJ_EG 17-18. The Lag of Grades Comparing Selfassessment with Actual Grade Corrected by Project Teacher in the Course 2017-18

A remarkable variety of results: $38 \%$ of the students agree with the same grade teacher has given them, while $58 \%$ put on a higher grade than they actually get (Fig. 2).

\section{DELAY OF RATINGS NOTES PROJECT- EGE 2017-18}

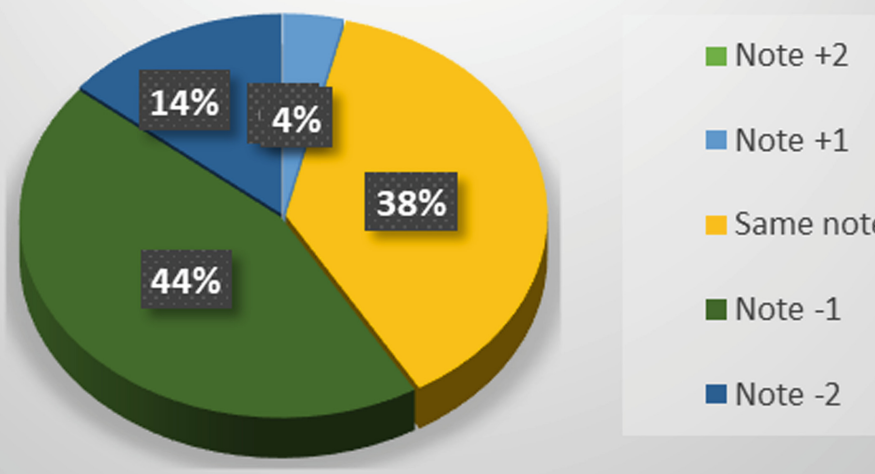

Fig. 2. DES_PROJ_EG 17-18. The lag of grades comparing self-assessment with actual grade corrected by the Project teacher in the course 2017-18

In the 2018-19 academic year, 220 surveys of participating students have been recorded and results are as follows:

\subsection{PROJ_EG 18-19. The Notes that Self-evaluate the Project in 2018-19 Course}

Extensively studied, $81 \%$ of students value their project with a high score, which $60 \%$ do with a note of noteworthy. Only one student among the 220 respondents believes that they have suspended the project (Fig. 3). 


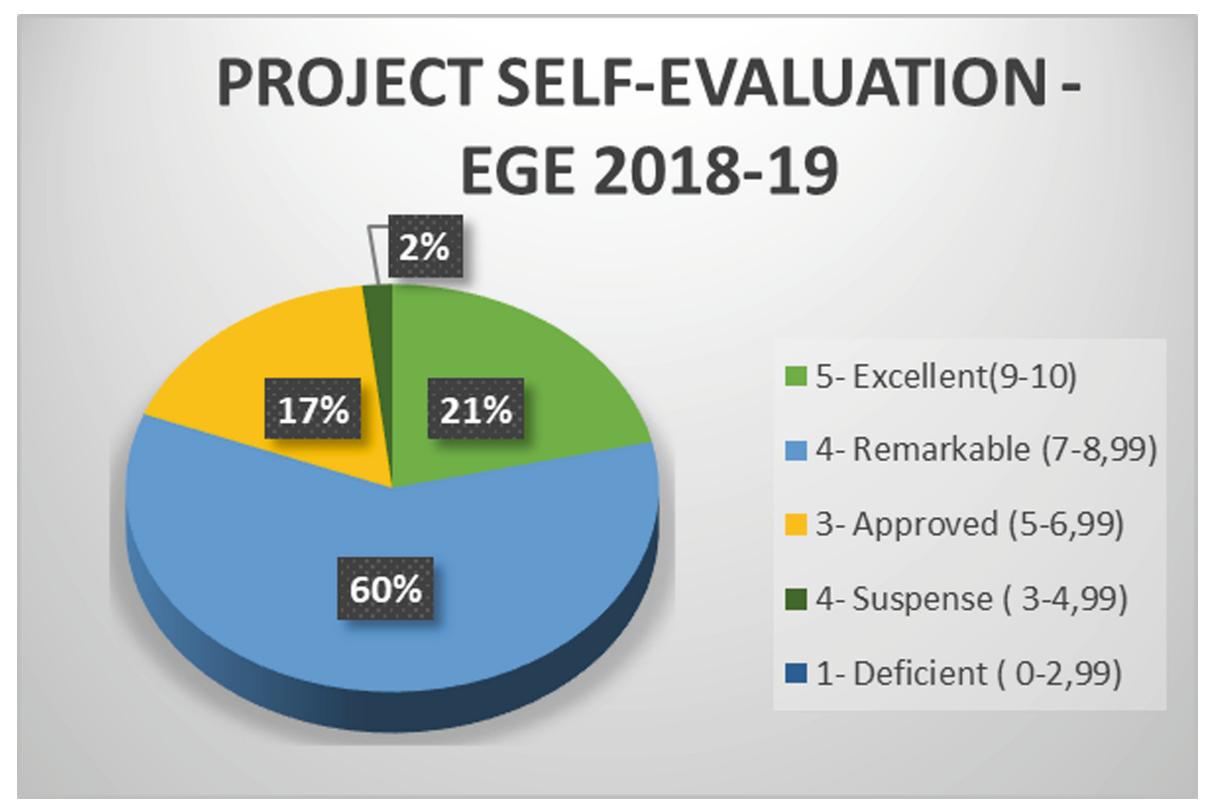

Fig. 3. PROJ_EG 18-19. Ratings Project notes in 2018-19 course

\subsection{DES_PROJ_EG 18-19. The Lag of Notes Comparing Self-assessment with Actual Score Corrected by the Project Teacher in 2018-19 Course}

Well-documented, $47 \%$ of students agree with the same grade given by teacher, while $41 \%$ put a higher grade they actually get (Fig. 4 ).

\section{DELAY OF RATINGS NOTES} PROJECT- EGE 2018-19

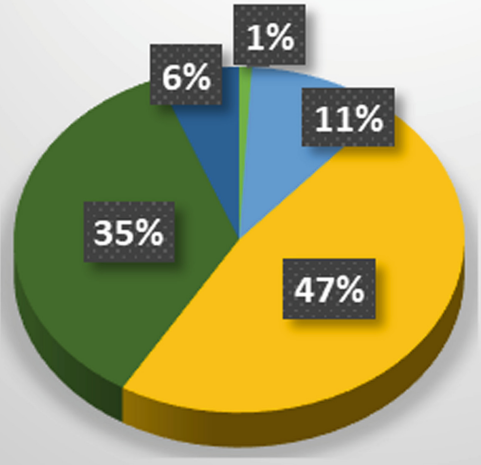

Note +2

Note +1

Same note

$\square$ Note -1

note -2

Fig. 4. DES_PROJ_EG 18-19. The lag of notes comparing self-assessment with actual grade corrected by the Project teacher in 2018-19 course 


\section{Conclusions}

\subsection{Conclusions About the Results}

Some qualitative conclusions about numerical results in self-evaluations are:

- Normally students score slightly better than teacher's assessment.

- The student knows how to better assess learning of different parts of the project.

- Each student knows how to properly assess their contribution to the group they belong.

- If working group dynamics is satisfactory, project results are also satisfactory. On the other hand, if dynamics of group work does not develop properly or there are conflicts within the group, it negatively affects progress and project results.

- Projecting in a group, does not condition its criteria to make a good self-assessment.

Regarding the quantitative results, it can be concluded that:

- The number of students who self-evaluate with an Excellent grade, which is a difficult grade to obtain, is higher in 2017-18 academic year (38\%) than in subsequent academic year $(21 \%)$.

- The coincidence of grade between what student self-evaluates and what professor issues is higher in 2018-19 academic year (47\%), than in first year of research $(38 \%)$. It is positively valued that in this second year we are reaching almost $50 \%$ of students who coincide in the grade.

- The gap of grade to one or two higher levels, that is, the student scores slightly better than the actual grade is lower in 2018-19 course (41\%) while in previous year it was $58 \%$, having much more lag of note.

- Considerable numerical results and well-known conclusions are obtained for selfevaluation, results in the 2018-19 course have been better than 2017-18 academic year.

\subsection{Research Conclusions}

Providing a self-assessment to Engineering students helps in their learning and helps them to be more responsible, both in individual work and in group projects. If projects are followed and tutored, after theoretical content and similar exercises, self-assessment is a tool reinforces their self-knowledge, to criticize other projects and be self-critical to reach the skills.

An essential work of self-evaluation always has a psychological component, an autonomous work and personal knowledge, therefore, it goes beyond strictly pedagogical work and content learning.

In these first 2 years of completion about self-assessment form, the results have not been binding in final grade of the subject. But results obtained in this second year, 2018-19, are better in terms of greater coincidence. When students self-evaluate, there is a smaller gap with the evaluation given by teacher. This is due to personalized tutorials and an exhaustive project monitoring. 


\section{References}

1. Pastor, V.M.: La participación del alumnado en la evaluación: La autoevaluación, la coevaluación y la evaluación compartida La participación del alumnado en la evaluación: la autoevaluación, la coevaluación y la evaluación compartida (2005)

2. Sambell, K., McDowell, L., Brown, S.: "But is it fair?": an exploratory study of student perceptions of the consequential validity of assessment. Stud. Educ. Eval. (1997). https://doi. org/10.1016/S0191-491X(97)86215-3

3. Palomares, A.: El modelo docente universitario y el uso de nuevas metodologías en la enseñanza, aprendizaje y evaluación. Revista de Educacion 355, 591-604 (2011). https://doi. org/10.4438/1988-592X-RE-2011-355-038

4. Jimenez Valverde, G., Llitjos Viza, A.: Methodological optimization of cooperative online environments (BSCW \& Synergeia) as Chemistry teaching aids in hypermedia authoring. Enseñanza de las Ciencias (2008)

5. Cadenato, A., Martinez, M., Gallego, I., Amante, B., Jordana, J., Sanchez, R.F., Farrerons, O., Isalgue, A., Fabregat, J.: Criterios para prácticas de evaluación de calidad. Una propuesta de Grapa-Rima. In VII Congrés Internacional Docència Universitària i Innovació: La universitat: una institució de la societat. La universidad: una institución de la sociedad. The University: an institution of Society (2012)

6. Ibarra Sáiz, M., Rodriguez Gómez, G.: Los procedimientos de evaluación como elementos de desarrollo de la función orientadora en la universidad. REOP - Revista Española de Orientación y Psicopedagogía (2010). https://doi.org/10.5944/reop.vol.21.num.2.2010.11558

7. Pujol-Ferran, A., Farrerons-Vidal, O.: L'autoavaluació en enginyeria. L'aplicació de l'autoavaluació en projectes del Grau d'Enginyeria Industrial com a eina d'avaluació i autoaprenentatge. Congrés Internacional Docència Universitària i Innovació (2018)

8. García Sanz, M.P.: La evaluación de competencias en Educación Superior mediante rúbricas: un caso práctico. Revista Electrónica Interuniversitaria de Formación del Profesorado (2014). https://doi.org/10.6018/reifop.17.1.198861

9. Crebert, G., Bates, M., Bell, B., Patrick, C.-J., Cargnolini, V.: Developing generic skills at university, during work placement and in employment: graduates' perceptions. High. Educ. Res. Dev. (2007). https://doi.org/10.1080/0729436042000206636 